\title{
Implementing drinking water feed additive strategies in post-weaning piglets, antibiotic reduction and performance impacts: case study
}

\author{
Juan Antonio Mesonero Escuredo ${ }^{1 *}$, Yvonne van der Horst $^{2}$, John Carr $^{3}$ and Dominiek Maes ${ }^{4}$
}

\begin{abstract}
Background: Piglets at weaning suffer many stressors such as sudden change of feed, change in group composition and the end of lactogenic immunity. These stressors may cause poor growth performance. There is a need for alternatives to support piglets during the weaning period. Organic acids are known to have a positive effect on performance through reducing the $\mathrm{pH}$ and their antimicrobial action.

Context \& purpose: The purpose was to study the effect of the inclusion of a free and buffered organic acid blend in drinking water on performance of weaned pigs.

Four-hundred and twenty pigs in a conventional herd were allocated after weaning to one of three treatments and monitored during 4 weeks: group (1) Full medication, group (2) organic acid blend + full medication, group (3) organic acid blend + reduced medication. Average daily gain, feed intake and water consumption was recorded at group level.

Results: During the overall study period live weight and average daily gain of the piglets was significantly higher $(P<0.001)$ for treatment (3) compared to (1) and (2) (Table 1). Live weight was significantly higher for treatment (3) compared to (1) from week 2 of the study (Fig. 1). No significant differences were found for average daily feed intake. FCR for treatment (3) improved by 1.0 compared to treatment $(1)$ in week $1(P<0.05)$, while in week 2 and 3 no significant differences were found (Table 2). Overall, FCR was with 0.3 difference significantly lower $(P=0.001)$ for treatment (3) than for (1) and (2) (Table 1). Pigs receiving organic acids in drinking water had significantly $(P<0.05)$ higher water consumption than group (1) in weeks 3 and 4 (Table 2).

Conclusion \& potential implications: The use of a blend of free and buffered organic acids together with a reduced medication program improves growth performance during the first month after weaning compared to a control with full medication and a combination between organic acids and full medication. This implies that organic acids could be used as a valid alternative for antibiotic reduction in post-weaning pigs. The treatment also increased the drinking water intake.
\end{abstract}

Keywords: Piglets, Organic acids, Additives, Drinking water, Post-weaning period, Nursery, Performance, Antibiotic reduction

Abbreviations: ADFI, Average daily intake; ADG, Average daily gain; d, Days; FCR, Feed conversion rate; MCFA, Medium chain fatty acids; med., Medication; OAs, Blend of free and buffered organic acids (Formic acid, acetic acid and ammonium formate); red., Reduced; SCFA, Short chain fatty acids; SED, Standard error of difference of the means; T X B, Treatment by block; Trtmt, Treatment

\footnotetext{
* Correspondence: jamesonero@outlook.es

${ }^{1}$ Resident European College of Porcine Health Management, University of

Ghent, Ghent, Belgium

Full list of author information is available at the end of the article
} 


\section{Background}

Weaned piglets are exposed to many stressors, such as abrupt change of feed, change in group composition and the end of lactogenic immunity $[11,20]$. As a consequence, malabsorption problems might occur resulting in poor growth performance and increased mortality. Antimicrobials have been used for more than 50 years to increase growth performance and to prevent piglet diseases after weaning $[7,10]$. The increasing resistance of bacteria against antibiotics has resulted in a ban on antibiotic growth promoters in feed in the European Union in 2006 (EU Regulation 1831/2003) and several programs have been developed worldwide until today to reduce the clinical application of antibiotics. This has urged the need for alternatives which have antibacterial and growth promoting effects, without inducing resistance.

Organic acids have been shown as viable growth promoters in swine diets $[16,17,21]$. The antimicrobial effect of organic acids in pigs is suggested to be achieved in several ways. Firstly, uptake of pathogenic bacteria can be reduced by lowering the $\mathrm{pH}$ of feed and water. Chaveerach et al. [3] demonstrated that survival of Campylobacter jejuni in a feed/water mixture declined to below detection limits within one hour of incubation when formic, propionic or acetic acid was added until pH 4.0 was reached. Organic acids are also suggested to reduce $\mathrm{pH}$-value in the stomach of recently weaned pigs [9]. A lower gastric $\mathrm{pH}$ results in a stronger biological barrier function of the stomach against bacterial transfer to the intestine and it could result in increased activity of proteolytic enzymes [9]. Furthermore, it has also been shown that Lactobacilli are better resistant to acidic conditions in the stomach, which possibly inhibits the colonization and proliferation of E.coli [5] through mutual exclusion. Secondly, undissociated forms of organic acids can penetrate the wall of the bacterial cell and once inside it will dissociate into anions and protons [4]. This will disrupt internal metabolism of bacteria and inhibit proliferation. In the review of Canibe et al. [1] several sources describe that the application of organic acidifiers in the diet can reduce the number of Coliform bacteria along the intestinal tract of piglets (testing method not specified in the review). Bacteria like Lactobacilli and Bifidobacterium spp. tolerate a larger change in internal $\mathrm{pH}$ and the bacteria will not suffer from the acid molecules that have entered the bacterial cell.

Organic acids can be applied to the pigs through water or through feed. Water intake of pigs is approximately 2-3 times as much as the intake of feed [13]. Therefore, application of organic acids through water will result in a higher level of acid intake and consequently a higher amount of acid reaching the intestinal tract of the animal when compared to application through feed when the acid is included at an equal concentration in both feed and water. Furthermore, supplying acids via water provides much more flexibility, since the dosage can be changed per day. This enables the farmer to adapt the dosage of acids to the needs of the animals.

In this study we investigated the effect of organic acids on the possibility to reduce medication without reducing performance. In most of the previous studies organic acids were tested alone instead of in combination and no comparison was made with application of medication.

The objective of the present study was to investigate the effect of application of a blend of free and buffered organic acids in the drinking water (Additional file 1) on performance of weaned piglets, both in the presence and absence of antibiotic medication used to control enteric disease.

\section{Materials and methods}

\section{Study farm and study animals}

The study was performed in the nursery of a commercial research facility at Westbrook, Qld (Australia). One-hundred and forty (140) weaned pigs (21 days Genetic hybrid slaughter line, Large with Landrace and Duroc mix from PIC) entered the facility each week with 3 weeks of entries being used, resulting in four-hundred and twenty (420) pigs in total in this study (Additional file 2).

The herd was positive for Mycoplasma hyopneumoniae and Actinobacillus Pleuropneumoniae (Serovar 15). The pigs were vaccinated against $M$. hyopneumoniae $(1 \mathrm{~mL} / \mathrm{pig}$ $\mathrm{M}+\mathrm{PAC}$, Merck Animal Health) at 3 and 9 weeks of age. Vaccination against A. Pleuropneumoniae $(2 \mathrm{~mL} /$ pig Porcilis APPvac, Merck Animal Health) was applied at 9 and 12 weeks of age and at 12 and 14 weeks of age the pigs were vaccinated against GnRF ( $2 \mathrm{~mL} /$ pig Improvac, Zoetis). Clinical problems due to Haemophilus parasuis were not present on the sow farm, only at the research facility. The most recent test on small intestine swabs for E.coli that was done on the research facility was O139:K88 positive.

Removal of pigs from the experimental groups was based on body condition and assessment of clinical state (i.e. alert vs. depressed/listless).

Penning was open galvanized paneling with fully-slatted plastic floor tiles. All pens in the nursery were of identical configuration $(1 \mathrm{~m} \times 2.8 \mathrm{~m})$.). A total of 30 pens were included in the study (420 piglets), ten pens per treatment (140 piglets), with 14 piglets per pen (one replica each pen). The climate control in the facility was achieved through natural ventilation by manually controlled side curtains. Radiant bar heaters were present in each pen with a temperature probe and controller for the block of ten pens. Water was supplied ad libitum via two nipple drinkers per pen. Feed was offered in pellet form to each individual pen via a round multi-space adjustable plastic transit feeder. Diets were offered ad libitum throughout the experimental period.

Before the pigs entered the facility, the water lines were flushed with the blend of organic acids during 1 week at a 
dosage of $2 \mathrm{~L}$ per $1000 \mathrm{~L}$ of water in order to start with a clean drinking water system.

\section{Experimental design}

Upon entry, pigs were sexed and graded into large, medium and small pigs and assigned a pen $(n=14)$. Pigs were weighed at pen-level (average entry weight $6.1 \pm 0.14 \mathrm{~kg}$ ) and allocated to treatment using a randomized block design with sex, weight and entry date as blocking factors. All piglets in the study received feed medication with Amoxycillin trihydrate dosed at $400 \mathrm{ppm}$ during the duration of the study to prevent problems with $H$. parasuis infections.

The below three treatments were applied:

1. NEO- Neomycin sulfate $300 \mathrm{ppm}$ in feed

2. $\mathrm{OA}+\mathrm{NEO}-\mathrm{OA}$ blend at $2 \mathrm{~L} / 1,000 \mathrm{~L}$ of water + Neomycin sulfate $300 \mathrm{ppm}$ in feed

3. OA - OA blend at $2 \mathrm{~L} / 1,000 \mathrm{~L}$ of drinking water

An individual block within the weaned facility consisted of ten pens per treatment with 14 pigs per pen. The block refers to the week of entry of the pigs, therefore we apply all treatments in all weeks as a way of accounting for this block. As we are applying, in this experiment, three treatments to ten pens each weeks, it's not always going to be possible to complete balance the treatments for weights. Whilst we are seeing main effects from treatments across the experiment, there is also a consistent block effect.

The organic acid blend consisted ${ }^{1}$ of formic acid, acetic acid and ammonium formate and was delivered at the rate of $2 \mathrm{~L} / 1,000 \mathrm{~L}$ of drinking water. This dosage was determined based on a water titration (Fig. 1). The water consumption was measured via individual water meters in each pen. Medications used in all treatments were administered in-feed under veterinary advice. Neomycin sulphate $(600 \mathrm{mg} / \mathrm{g}-0.5 \mathrm{~kg} / \mathrm{t}$ (300 ppm) in feed) was applied to prevent problems with post-weaning E.coli infections.
Samplings occurred as a response to a period of increased morbidity or mortality on farm. Samples were obtained from euthanized pigs showing signs of significant ill-thrift. Two swabs from intestines showing gross pathology of E.coli infection were cultured and one lung swab was cultured from a set of lungs showing signs of congestion. Sensitivity test indicates E. coli was sensitive to Neomycin and Ceftiofur, but resistant to other antibiotics. No lung pathogens were cultured. Hemolytic E.coli was cultured from small intestine swabs, it was resistant to Amoxycillin, Apramycin, Florfenicol, Lincomycin and streptomycin combination, Trivetrin. The study lasted for 4 weeks.

\section{Parameters of comparison Average daily weight gain}

Pens were weighed weekly and the average of the number of piglets in the pen was calculated, averaged over 7 days. ADG was calculated every 7 days, and was on the basis of average pig live weight of each pen at the start and the end of week.

\section{Feed conversion ratio}

Weekly feed disappearance was calculated from feed deliveries and weighed refusal on the final day of the week. ADFI was calculated by dividing the total feed consumption in a week by the number of pig days. FCR is calculated by dividing ADFI by ADG.

\section{Morbidity}

Morbidity was determined by an extended period (3 days) of listlessness based on posture and behavior.

\section{Data and statistical analyses}

The null hypothesis was that the inclusion of OA to the drinking water could not enhance growth performance (i.e. body weight and feed conversion ratio) compared to treatment NEO nor reduce the reliance on medication.

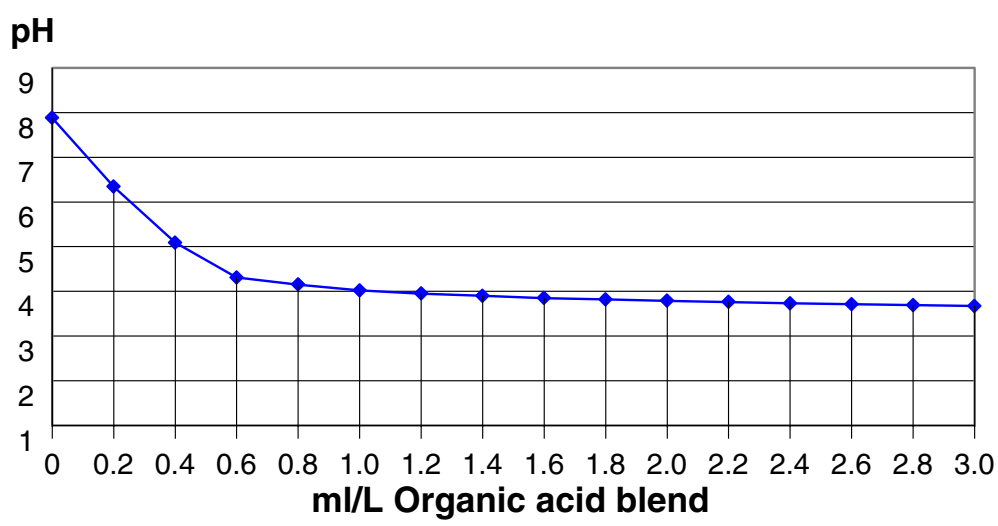

Fig. 1 Water titration results of the drinking water with a blend of formic acid, acetic acid and ammonium formate of the weaned pigs prior to onset of this study 
Data were analyzed via an unbalanced ANOVA with week of entry as a blocking factor and entry weight as a covariate, pairwise differences between treatments were determined by LSD $(P<0.05)$. Removals were tested for significance via Chi-square analysis $(P<0.05)$. A sample size analysis (one-sided t-test; significance level $5 \%$; power $80 \%$ ) was ran in order to test the statistical power of the study and showed that the study had adequate sample size for the differences found.

Mortality analysis was done through Pearson's chi-square of sample distribution, comparing total deaths/removals and live pigs at the end of experimental period (GenStat $15^{\text {th }}$ edition (VSN International, Hemel Hempstead, UK)).

\section{Results}

Pigs receiving the OA treatment were significantly heavier at the end of the experimental treatment than the NEO and $\mathrm{OA}+\mathrm{NEO}$ treatments, with a difference of $1 \mathrm{Kg}$ between the OA and NEO group (Table 1). The pigs from the OA treatment tended to grow faster than the NEO and OA + NEO treatments during each week, but the difference was only significant during week $4 \quad(P<0.001)$ (Table 2). Over the total duration of the study average daily gain was higher for the OA treatment compared to the NEO and OA + NEO treatment $(P<0.001)$ (Table 1$)$. There was no significant difference in feed intake between treatments over the complete duration of the trial or per week (Tables 1 \& 2). Over the total duration of the study, feed conversion ratio was significantly better for the OA treatment compared to the NEO and OA + NEO treatment (Table 1). Feed conversion ratio for the OA treatment improved by 1.0 compared to the NEO and OA + NEO treatment in week $1(P<0.05)$, while in week 2 and 3 no significant differences were found. In the fourth week of the study feed conversion ratio was improved by 0.3 in the OA treatment compared to the NEO and OA + NEO group $(P=0.001)$ (Table 2$)$. In the results per week live weight in week 4, feed conversion ratio in week 1 and average daily gain in week 4 showed significant interactions with blocking factors (sex, weight and entry date). The cumulative data showed a significant interaction with blocking factors for FCR after week 1 and 2 and for average daily gain after week 4 .

Pigs receiving the $\mathrm{OA}$ and the $\mathrm{OA}+\mathrm{NEO}$ treatment in water had significantly higher water consumption than the NEO in weeks 3 and 4 (Table 3).

Mortality and morbidity rates were highest in the group receiving the OA treatment $(P<0.05)$. No difference was found between the NEO and OA + NEO treatment (Table 1).

\section{Discussion}

In this study it was shown that application of organic acids in drinking water of piglets over a period of 4 weeks improved performance when levels of medication are reduced. Significant improvements are found in final weight, average daily gain and feed conversion ratio. An increase in mortality rates was found in the group with organic acids with reduced medication.

\section{Weight and average daily gain}

The increasing effects of organic acids on live weight and average daily gain are commonly seen in studies with organic acids in the diet. In general, literature data show a similar effect of dietary organic acids in young piglets. Kirchgessner et al. 1992 and Kim et al. 2004 found that supplementation of formic acid at levels up to $1.2 \%$ in diets of weaning piglets of 6 to $12 \mathrm{~kg}$ of body weight improved growth rate to a maximum of $31 \%$. At concentrations higher than $1.2 \%$ the effect of formic acid on growth was less efficient. Lawlor et al. [12] demonstrated that increases in ADG occurred in response to inclusion of $0.2 \%$ fumaric acid in the diet mainly in the initial 2 weeks post weaning, and confirmed that these

Table 1 Cumulative average daily gain (ADG), average daily feed intake (ADFI), feed conversion ratio (FCR) per week of 140 weaned piglets (21 days) supplied with or without an organic acid $(\mathrm{OA})$ blend in the drinking water and with full or reduced medication program in the feed

\begin{tabular}{|c|c|c|c|c|c|c|c|}
\hline & Control & $\mathrm{OA}+\mathrm{NEO}$ & $\mathrm{OA}$ & SED & Trtmt & Block & $T \times B$ \\
\hline Live weight & $12.5^{\mathrm{a}}$ & $12.8^{\mathrm{a}}$ & $13.5^{\mathrm{b}}$ & 0.24 & $<0.001$ & $<0.001$ & 0.008 \\
\hline ADG & $0.228^{a}$ & $0.238^{a}$ & $0.265^{b}$ & 0.009 & $<0.001$ & 0.008 & 0.008 \\
\hline ADFI & 0.40 & 0.40 & 0.39 & 0.024 & 0.738 & 0.497 & 0.229 \\
\hline FCR & $1.76^{\mathrm{a}}$ & $1.70^{\mathrm{a}}$ & $1.46^{b}$ & 0.073 & 0.001 & 0.520 & 0.113 \\
\hline Mortality & 0 & 3 & 3 & & & & \\
\hline Morbidity & 3 & 4 & 9 & & & & \\
\hline Total Mortality + Morbidity & $3^{a}$ & $7^{a b}$ & $12^{b}$ & & & & \\
\hline
\end{tabular}

${ }^{\mathrm{a}, \mathrm{b}}$ Means in a row with different superscripts differ significantly $(P<0.05)$; Removals were tested for significance via Chi-square analysis, $\mathrm{X} 2(2$, $N=140)=5.95, P=0.051$

1. Control - Neomycin sulfate $300 \mathrm{ppm}$ in feed

2. OA + NEO - OA blend at $2 \mathrm{~L} / 1,000 \mathrm{~L}$ of water + Neomycin sulfate $300 \mathrm{ppm}$ in feed

3. OA - OA blend at $2 L / 1,000 L$ of water 
Table 2 Data per week with or without additives, with or without reducing antibiotics; Live weight, average daily gain (ADG), average daily feed intake (ADFI), feed conversion ratio (FCR) per week of 140 weaned piglets (21 days) supplied with or without an organic acid $(\mathrm{OA})$ blend in the drinking water and with full or reduced medication program in the feed

\begin{tabular}{|c|c|c|c|c|c|c|c|c|}
\hline & & Control & $\mathrm{OA}+\mathrm{NEO}$ & $\mathrm{OA}$ & SED & Trtmt & Block & $T \times B$ \\
\hline \multirow[t]{5}{*}{ Live weight } & Entry & 6.2 & 6.1 & 6.0 & 0.37 & 0.893 & 0.266 & 0.809 \\
\hline & Week 1 & 6.5 & 6.5 & 6.7 & 0.08 & 0.074 & $<0.001$ & 0.294 \\
\hline & Week 2 & $8.0^{\mathrm{a}}$ & $8.1^{\mathrm{ab}}$ & $8.3^{b}$ & 0.12 & 0.026 & $<0.001$ & 0.086 \\
\hline & Week 3 & $9.8^{\mathrm{a}}$ & $10.0^{\mathrm{a}}$ & $10.3^{b}$ & 0.22 & 0.043 & $<0.001$ & 0.188 \\
\hline & Week 4 & $12.5^{\mathrm{a}}$ & $12.8^{\mathrm{a}}$ & $13.5^{\mathrm{b}}$ & 0.24 & $<0.001$ & $<0.001$ & 0.008 \\
\hline \multirow[t]{3}{*}{ Week 1} & ADG & 0.052 & 0.056 & 0.076 & 0.012 & 0.081 & 0.073 & 0.310 \\
\hline & ADFI & 0.16 & 0.16 & 0.17 & 0.014 & 0.458 & 0.200 & 0.747 \\
\hline & FCR & $3.51^{\mathrm{a}}$ & $3.04^{\mathrm{ab}}$ & $2.48^{b}$ & 0.398 & 0.043 & 0.073 & 0.032 \\
\hline \multirow[t]{3}{*}{ Week 2} & ADG & 0.218 & 0.220 & 0.232 & 0.010 & 0.182 & 0.003 & 0.108 \\
\hline & ADFI & 0.33 & 0.33 & 0.32 & 0.020 & 0.941 & 0.180 & 0.513 \\
\hline & FCR & 1.53 & 1.49 & 1.40 & 0.079 & 0.151 & $<0.001$ & 0.296 \\
\hline \multirow[t]{3}{*}{ Week 3} & ADG & 0.266 & 0.282 & 0.298 & 0.018 & 0.145 & $<0.001$ & 0.399 \\
\hline & ADFI & 0.48 & 0.48 & 0.45 & 0.032 & 0.467 & 0.780 & 0.144 \\
\hline & FCR & 1.84 & 1.73 & 1.54 & 0.115 & 0.059 & $<0.001$ & 0.508 \\
\hline \multirow[t]{3}{*}{ Week 4} & ADG & $0.403^{\mathrm{a}}$ & $0.419^{a}$ & $0.478^{b}$ & 0.018 & $<0.001$ & 0.003 & 0.015 \\
\hline & ADFI & 0.64 & 0.67 & 0.63 & 0.041 & 0.475 & 0.256 & 0.145 \\
\hline & FCR & $1.62^{\mathrm{a}}$ & $1.62^{\mathrm{a}}$ & $1.31^{\mathrm{b}}$ & 0.081 & 0.001 & 0.022 & 0.099 \\
\hline
\end{tabular}

1. Control - Neomycin sulfate $300 \mathrm{ppm}$ in feed

2. $\mathrm{OA}+\mathrm{NEO}-\mathrm{OA}$ blend at $2 \mathrm{~L} / 1,000 \mathrm{~L}$ of water + Neomycin sulfate $300 \mathrm{ppm}$ in feed

3. OA - OA blend at $2 \mathrm{~L} / 1,000 \mathrm{~L}$ of water

a,b Means in a row with different superscripts differ significantly $(P<0.05)$; ADG, average daily gain; ADFI, average daily feed intake; FCR, feed conversion ratio; SED, standard error of difference of the means

effects have been noted previously by Radecki et al. [18] and Giesting et al. [6]. It has been suggested that the improvement in growth is the result of a reduced $\mathrm{pH}$ in the stomach induced by the organic acids. As a result, there is a better barrier function of the stomach against harmful bacteria to enter into the small intestine and a more efficient protein digestion $[9,22]$. In a metaanalysis by Partanen and Mroz [17], it was shown that organic acids generally improved growth performance of piglets, but the effects vary greatly. Reasons for the varying results relate to dosage and type of acids used, composition of basal diet, age of piglets, and existing levels of performance [19]. The latter might also explain the interaction found between treatment and block for live weight and average daily gain in weekly and cumulative data.

\section{Feed intake}

Feed intake was not affected as a result of the OA and $\mathrm{OA}+\mathrm{NEO}$ treatment in the current study. The organic acids were applied in the drinking water instead of in the feed, therefore less effects on feed intake could be expected compared to when the acids would have been applied in the feed. Several former studies report on the effect of acids in the feed on feed intake. Lawlor et al. [12] showed that in two out of three experiments feed intake was not affected by feeding diets containing fumaric acid or calcium formate. Increases in feed intake and average daily gain were mainly found in the initial 2 weeks after weaning [17]. Literature data indicate that a higher feed intake might be related to better diet palatability [17], but the extent of the effect is dependent on the type of organic acid added. The sources used in the

Table 3 Water consumption L/pen/week; Water usage of 140 weaned piglets (21 days) supplied with or without an organic acid $(\mathrm{OA})$ blend in the drinking water and with full or reduced medication program in the feed (L/pen/week)

\begin{tabular}{lcccccccc}
\hline & & Control & Control + OAs & OAs + red. & SED & Treatment & Block & Tx B \\
\hline Water consumption & Week 1 & 7.5 & 8.4 & 9.2 & 2.05 & 0.628 & 0.005 & 0.967 \\
& Week 2 & 8.7 & 17.2 & 13.9 & 3.61 & 0.079 & 0.021 & 0.639 \\
& Week 3 & $11.4^{\mathrm{a}}$ & $24.5^{\mathrm{b}}$ & $23.8^{\mathrm{b}}$ & 3.67 & 0.004 & 0.691 & 0.416 \\
& Week 4 & $13.9^{\mathrm{a}}$ & $31.6^{\mathrm{b}}$ & $28.4^{\mathrm{b}}$ & 5.65 & 0.014 & 0.880 & 0.824 \\
\hline
\end{tabular}


Table 4 Basic feed formula data

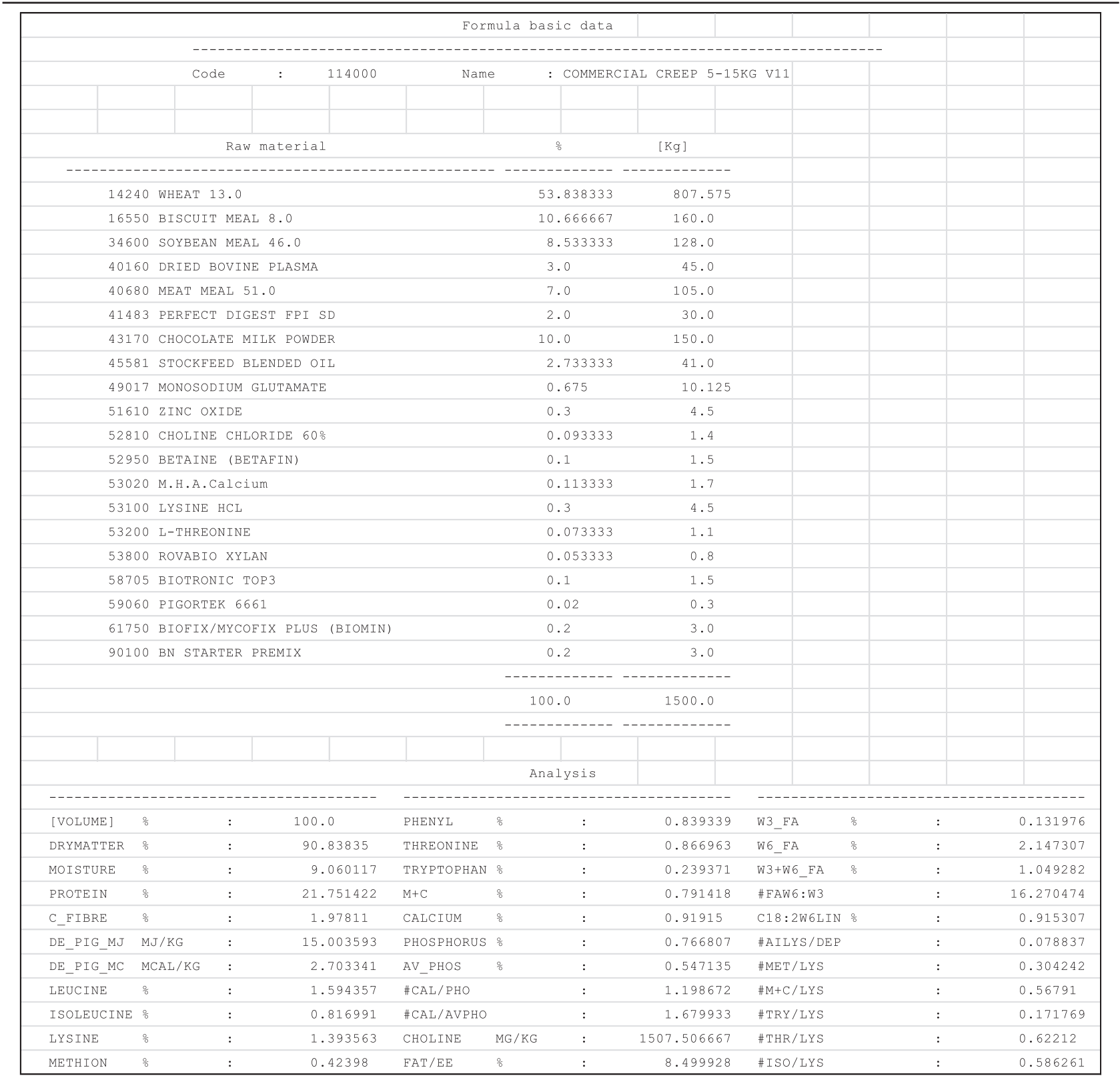

review of Partanen and Mroz [17] indicate that in general formic acids and formates have a positive effect, fumaric no effect and citric acid had a negative effect.

\section{Feed conversion ratio}

Overland et al. [15] found that dietary addition of formic, benzoic and sorbic acid in the diet significantly improved FCR compared with a NEO group without dietary organic acids. Canibe (2005) demonstrated that pigs in the growth phase of 27 to $99 \mathrm{~kg}$ BW had a better G:F when supplemented with formic acid than those fed a diet without formic acid (392 $\mathrm{g} / \mathrm{kg}$ vs. $351 \mathrm{~g} / \mathrm{kg}$ respectively, $P=0.02$ ).
The more efficient utilization of feed is also expected to be the result of the stronger $\mathrm{pH}$ reduction and consequent increase in level of active protein digestion enzymes in the stomach.

\section{Water consumption}

In the present study, water consumption of the piglets was higher for the OA and OA + NEO, with significant differences found in week 3 and 4 of the study. Houben et al. [8] found that water consumption of pigs supplied with water with a low pH-value (3.4-3.8) was clearly higher compared to pigs supplied with non-acidified 
water ( $\mathrm{pH}$ value 6.7-7.8). It is not clear from the present study if the higher intake is the result of a better palatability because of the acids, since no opportunity was given for choosing between acidified and non-acidified water and the sodium content of water differed between treatments.

\section{Mortality and medication}

Mortality was significantly higher for the OA with reduced medication treatment compared to the full medication treatment and the control. Gross post-mortems on farm were consistent with $H$. parasuis in two deaths in $\mathrm{NEO}+$ $\mathrm{OA}$ and three deaths in Selko-pH treatment. 1 death within the NEO + OA treatment was not able to be determined through post-mortem. This shows that the mortality was due to causes that cannot be controlled by organic acids.

\section{Limitations of the study}

In the current study only one piglet herd was included, which may affect the results compared to when multiple herds from different origin are used since the animals can have a different status at the start of the trial. Because there was no control treatment without antibiotics, there is no data about the performance of pigs without any treatment.

The first 4 weeks are the most important in the growth and development of piglets, therefore only these weeks were included in the trial. Therefore, there are no data available on the weeks after that.

No data is available on the microbiota composition and pathogenic bacteria levels in the feces of the pigs, therefore no conclusion can be given on the effect of the $\mathrm{OA}$ or $\mathrm{OA}+\mathrm{NEO}$ treatments on the microbial balance of the pigs. In the literature several sources indicate a positive effect of organic acids on the microbiota of pigs $[2,14,15,23]$.

\section{Conclusions}

The use of a blend of free and buffered organic acids improved live weight, ADG and FCR compared to a combination of the blend of acids with Neomycin against post-weaning $E$. coli infections during the first month after weaning. This implies that OA could be used as a valid alternative for antibiotic medication in pigs postweaning. The treatment also increased the drinking water intake. Further research should be conducted including more herds with different management practices to confirm the present results, and to elucidate the mechanisms that are responsible for the beneficial effects.

\section{Endnotes}

${ }^{1} 35 \%$ formic acid, $9 \%$ acetic acid, $25 \%$ ammonium formate, $<1 \%$ copper sulphate.

\section{Additional files}

Additional file 1: Water analysis. (PDF $330 \mathrm{~kb}$ )

Additional file 2: Facility Pictures. (ZIP $2811 \mathrm{~kb}$ )

\section{Acknowledgements}

Thanks to Christine Clark and Jess Naylor from Auspac (Australia) for their support looking for the facility, compiling the data, plus patience and professionalism.

\section{Authors' contributions}

JAME, YvdH, JC, DM. All authors read and approved the final manuscript.

\section{Competing interests}

The case was performed by an independent commercial research facility at Westbrook, QLd (Australia), founded by AusPac Ingredients (Australia), Trouw nutrition Asia (Indonesia) and Nutreco (The Netherlands).

\section{Consent for publication}

Consent to participate under the Ethics, consent and permissions. Confirming that consent to publish has been obtained to report data.

\section{Ethics approval and consent to participate}

Statement of ethics approval with the committee's reference number: Approval sought through CHM Alliance AEC (CHM PP 58/14).

\section{Author details}

${ }^{1}$ Resident European College of Porcine Health Management, University of Ghent, Ghent, Belgium. ²Nutreco BV, Trouw Nutrition Selko, Jellinghausstraat 24, Tilburg, P.O. Box 42175004 JE Tilburg, The Netherlands. ${ }^{3}$ Howells Veterinary Services, Easingwold, UK. ${ }^{4}$ Faculty of Veterinary Medicine, Department of Reproduction, Obstetrics and Herd Health, Unit Porcine Health Management, Ghent University, Salisburylaan 133, B-9820 Merelbeke, Belgium.

Received: 28 April 2016 Accepted: 12 August 2016

Published online: 16 October 2016

\section{References}

1. Canibe N, Engberg RM, Jensen BB. An overview of the effect of organic acids on gut flora and gut health. Workshop proceedings; Alternatives to feed antibiotics and coccidiostats in pigs and poultry (AFAC). 2001.

2. Canibe N, Hojberg O, Hojsgaard S, Jensen BB. Feed physical form and formic acid addition to the feed affect the gastrointestinal ecology and growth performance of growing pigs. J Anim Sci. 2005;83:1287-302.

3. Chaveerach P, Keuzenkamp DA, Urlings HAP, Lipman LJA, van Knapen F. In vitro study on the effect of organic acids on Campylobacter jejuni/coli populations in mixtures of water and feed. Poult Sci. 2002;81:621-8.

4. Cherrington CA, Hinton M, Chopra I. Effect of short chain organic acids on macromolecular synthesis in Escherichia coli. J Bacteriol. 1990;68:69-74.

5. Fuller R. The importance of Lactobacilli in maintaining normal microbial balance in the crop. Br Poult Sci. 1977;18:85-94.

6. Giesting DW, Roos MA, Easter RA. Evaluation of the effect of fumaric acid and sodium bicarbonate addition on performance of starter pigs fed diets of different types. J Anim Sci. 1991;69:2489-96.

7. Gustafson RH, Bowen RE. Antibiotic use in animal agriculture. J Appl Microbiol. 1997:83:531-41.

8. Houben MAM, van Nes A, Tobias TJ. Water palatability, a matter of taste. Porcine Health Management. 2015;1-10.

9. Kim YY, Kil DY, Oh HK, Han IK. Acidifier as an alternative material to antibiotics in animal feed. Asian-Aust J Anim Sci. 2004;18:1048-60.

10. Kim HB, Borewicz K, White BA, Singer RS, Sreevatsan S, Tu ZJ, Isaacson RE. Microbial shifts in the swine distal gut in response to the treatment with antimicrobial growth promoter, tylosin. PNAS. 2012;109:15485-90.

11. Lallès JP, Bosi P, Smidt H, Stokes CR. Nutritional management of gut health in pigs around weaning. Proc Nutr Soc. 2007;66:260-8.

12. Lawlor PG, Lynch PB, Caffrey PJ. Effect of fumaric acid, calcium formate and mineral levels in diets on the intake and growth performance of newly weaned pigs. Irish J Agr Food Res. 2006;45:61-71. 
13. Li YZ, Chénard L, Lemay SP, Gonyou HW. Water intake and wastage at nipple drinkers by growing-finishing pigs. J Anim Sci. 2005;83:1413-22

14. Looft T, Johnson TA, Allen HK, Bayles DO, Alt DP, Stedtfeld RD, Sul WJ, Stedtfled TM, Chai B, Cole JR, Hashsham SA, Tiedie JM, Stanton TB. In-feed antibiotic effects on the swine intestinal microbiome. PNAS. 2012;109:1691-6.

15. Overland M, Kjos NP, Borg M, Skjerve E, Sorum H. Organic acids in diets for entire male pigs: effect on skatole level, microbiota in digesta and growth performance. Livest Sci. 2008;115:169-78.

16. Papatsiros VG, Billinis V. The prophylactic use of acidifiers as antibacterial agents in swine. In: Bobbarala V, editor. Antimicrobial agents. 2012. p. 295-310

17. Partanen $\mathrm{KH}, \mathrm{Mroz} Z$. Organic acids for performance enhancement in pig diets. Nutr Res Rev. 1999;12:117-45.

18. Radecki SV, Juhl MR, Miller ER. Fumaric and citric acids as feed additives in starter pig diets: effect on performance and nutrient balance. J Anim Sci. 1988:66:2594-605

19. Ravindran V, Kornegay ET. Acidification of weaner pig diets: a review. J Sci Food Agric. 1993:62:313-22.

20. Spreeuwenberg MAM, Verdonk JMAJ, Gaskins HR, Verstegen MWA. Small intestine epithelial barrier function is compromised in pigs with low feed intake at weaning. J Nutr. 2001;131:1520-7.

21. Upadhaya SD, Lee KY, Kim $1 \mathrm{H}$. Protected organic acid blends as an alternative to antibiotics in finishing pigs. Asian-Aust J Anim Sci. 2014;27:1600-7.

22. Van Winsen RL, Urlings BAP, Lipman LJA, Snijders JMA, Keuzenkamp D, Verheijden JHM, Van Knapen F. Effect of fermented feed on the microbial population of the gastrointestinal tract of pigs. Appl Environ Microbiol. 2001;67:3071-6.

23. Zentek J, Ferrara F, Pieper R, Tedin L, Meyer W, Vahjen W. Effects of dietary combinations of organic acids and medium chain fatty acids on the gastrointestinal microbial ecology and bacterial metabolites in the digestive tract of weaning piglets. J Anim Sci. 2013;91:3200-10.

\section{Submit your next manuscript to BioMed Central and we will help you at every step:}

- We accept pre-submission inquiries

- Our selector tool helps you to find the most relevant journal

- We provide round the clock customer support

- Convenient online submission

- Thorough peer review

- Inclusion in PubMed and all major indexing services

- Maximum visibility for your research

Submit your manuscript at www.biomedcentral.com/submit

) Biomed Central 